\title{
Delivery of salbutamol to nonventilated preterm infants by metered- dose inhaler, jet nebulizer, and ultrasonic nebulizer
}

\author{
T.F. Fok, K. Lam, P.C. Ng, T.F. Leung, H.K. So, K.L. Cheung, W. Wong
}

Delivery of salbutamol to nonventilated preterm infants by metered-dose inhaler, jet nebulizer, and ultrasonic nebulizer. T.F. Fok, K. Lam, P.C. Ng, T.F. Leung, H.K. So, K.L. Cheung, W. Wong. OERS Journals Ltd 1998.

ABSTRACT: To identify the most efficient device for the delivery of bronchodilator aerosol to nonventilated preterm infants with chronic lung disease, we compared the metered dose inhaler (MDI) used in conjunction with a non-valved spacer, an ultrasonic nebulizer with a small medication cup, and two jet nebulizers.

The subjects were enrolled in two double-blind randomized crossover studies. In study $A(n=10)$, each infant was given a nominal dose of $200 \mu \mathrm{g}$ of salbutamol by a MDI (Ventolin ${ }^{\circledR}$ ) at $4 \mathrm{~h}$ intervals, and in random sequence via an Aerochamber (Neonatal Aerochamber $\left.{ }^{\circledR}\right)$ with its one-way valve removed, an ultrasonic nebulizer with a small cone-shaped medication cup (Siemens Electronics), and a jet nebulizer (Sidestream). Their functional residual capacity (FRC) and static respiratory system mechanics were measured before, and at $15,30,60$, and 120 min after aerosol delivery. Study $B(n=10)$ was carried out in an identical manner, but with a different jet nebulizer (Hudson).

In both studies, administration of salbutamol aerosol via the MDI Aerochamber or ultrasonic nebulizer resulted in a significantly greater reduction in respiratory system resistance than via jet nebulizers. Furthermore, the use of MDI Aerochamber or ultrasonic nebulizer was associated with a greater degree of post-treatment tachycardia and improvement in FRC. The bronchodilating effect of salbutamol delivered via the ultrasonic nebulizer appeared to be slightly greater than that via the MDI-Aerochamber, receiving significance only in Study $B$.

We conclude that both the metered-dose inhaler used with a nonvalved Aerochamber and the ultrasonic nebulizer with a small medication cup are both more efficient than the jet nebulizers in preterm infants.

Eur Respir J 1998; 12: 159-164.
Dept of Paediatrics, The Chinese University of Hong Kong, Prince of Wales Hospital, Hong Kong.

\section{Correspondence: T.F. Fok}

Dept of Paediatrics

Prince of Wales Hospital

Shatin

Hong Kong

Fax: 85226489134

Keywords: Aerosol jet nebulizer

metered-dose inhaler

preterm infants

salbutamol

ultrasonic nebulizer

Received: December 41997

Accepted after revision April 211998
Bronchodilator aerosols are commonly used for the treatment of bronchiolar constriction associated with chronic lung disease of the newborns [1-9]. The aerosols may be delivered by a metered dose inhaler (MDI) used in conjunction with a spacer device, a jet nebulizer, or an ultrasonic nebulizer. MDIs and jet nebulizers, currently the most frequently used aerosol delivery devices in these patients, have been extensively evaluated in in vitro neonatal filter studies, animal models and in ventilated infants. All results showed a relatively small lung deposition of $0.5-2 \%$ of the nominal dose [10-18]. There is, however, little information on their use in nonventilated infants.

In a group of older infants with wheezy symptoms, SALMON et al. [19] have demonstrated that aerosol deposition in their lungs was small and variable following delivery by either MDI or jet nebulizer, and ranged from $0.3-1.5 \%$ of the delivered dose. The same devices have been compared in nonventilated newborns with bronchopulmonary dysplasia in two recent studies. One study showed that $200 \mu \mathrm{g}$ of salbutamol delivered by the MDIAerochamber had a similar bronchodilating effect to that of $600 \mu \mathrm{g}$ delivered by the jet nebulizer [20]. This finding concurred with that of a study which directly measured the pulmonary deposition of radiolabelled salbutamol delivered by the devices. In this latter study, although the
MDI-Aerochamber was able to deliver a greater amount of radiolabelled salbutamol to the infants' lungs, the actual amount of deposition from the device was small, being $<1 \%$ of the actuated dose [12].

In all the above studies, aerosol delivery by the Aerochamber might have been impaired by the built-in oneway non-rebreathing valve at the device's outlet. In a group of infants with chronic lung disease, we have recently demonstrated that aerosol delivery via the spacer device could be substantially increased by removing the valve [21]. It is possible that the tidal volumes of preterm infants are too small to open the valve effectively, which may act as a baffle, resulting in aerosol loss due to impaction.

Compared to the MDI or jet nebulizer, there is relatively little information on the use of the ultrasonic nebulizer in small infants, and the few studies available are on ventilated subjects. Two earlier deposition studies have shown that the device has a relatively low efficiency similar to that of the jet nebulizers $[11,15]$. The efficiency could, however, be increased significantly by nebulizing the medication from a small cone-shaped medication cup with a tapered bottom that has recently become commercially available. In a recent study on a ventilated rabbit lung model, it was shown that the deposition of radiolabelled 
salbutamol generated from the small cup was $>3$ times that from the round bottom standard reservoir, and $>5$ times that from either the MDI spacer or the jet nebulizer [22]. The tapered bottom of the small cup results in a smaller "dead volume" and a more complete aerosolization of the medication. Being completely immersed in the coupling fluid, it might also allow better transmission of vibration energy to its contents, resulting in higher aerosol output. This small-cup device has, however, not been tested in nonventilated, spontaneously breathing infants.

In the following studies, we compared the ultrasonic nebulizer-small cup device with the MDI-Aerochamber and two different models of jet nebulizer for their efficacy in delivering salbutamol aerosol to preterm infants with chronic lung disease. The Aerochamber was modified by removing its one-way nonrebreathing valve. The pharmacological effects of a standard nominal dose of the bronchodilator delivered by each of the devices were used as the outcome measures.

\section{Subjects and methods}

\section{Subjects}

Preterm infants diagnosed consecutively to have chronic lung disease were enrolled after informed parental consent if they fulfilled the following criteria: 1) gestation $<32$ weeks; 2) birth weight $<1500 \mathrm{~g}$; 3) postnatal age Š4 weeks; 4) requiring mechanical ventilation for treatment of respiratory distress syndrome for at least 3 days during the first week of life; 5) chest radiograph showing changes consistent with chronic lung disease [23, 24]; 6) oxygen dependency at time of enrolment; and 7) respiratory status and oxygen requirement being stable for at least $24 \mathrm{~h}$. Infants with anatomical abnormalities of the airway were excluded. The studies were approved by the Ethics Committee for Clinical Research, The Chinese University of Hong Kong.

A total of 20 infants were studied. In the first 10 infants enrolled (Study A), the therapeutic effects of salbutamol aerosol delivered by a MDI (Ventolin® MDI, Glaxo Wellcome, UK), an ultrasonic nebulizer (Siemens Electronics Inc., Sweden) and a jet nebulizer (Sidestream jet nebulizer, MedicAid, UK) were compared using a double-blind randomized cross-over design. The study was repeated in the second 10 infants enrolled (Study B) using the same MDI and ultrasonic nebulizer but a different jet nebulizer (Hudson nebulizer, USA). At four hour intervals, and in random sequence, each infant was given a nominal dose of $200 \mu \mathrm{g}$ salbutamol aerosol by each device through a face mask held tightly over the infant's face covering the nose and mouth.

\section{Aerosol delivery}

MDI aerosol was delivered through a spacer device (Neonatal Aerochamber ${ }^{\circledR}$, Trudell, Canada) that had been modified by removing its one-way valve at the outlet. The face mask of the spacer was replaced with a smaller Laerdal Resuscitation Mask (Laerdal, Stavanger, Norway) to ensure a tighter fit onto the infant's face. Two puffs of salbutamol aerosol (100 $\mu$ g salbutamol per puff) were actuated at end-expiration 1 min apart, and the infant was allowed to breathe into the Aerochamber for $1 \mathrm{~min}$ before the system was removed. The MDI canister was shaken vigorously for at least $10 \mathrm{~s}$ before each actuation.
The jet and ultrasonic nebulizers were connected to a Laerdal face mask through a T-connector so that the excess gas flow could escape through the efferent limb of the connector. The Sidestream and Hudson jet nebulizers both operated at a flow rate of $6 \mathrm{~L} \cdot \mathrm{min}^{-1}$ as recommended by the manufacturers. Two hundred micrograms $(0.2 \mathrm{~mL})$ of salbutamol respirator solution (Ventolin ${ }^{\circledR}$, Glaxo Wellcome) diluted to $4 \mathrm{~mL}$ with isotonic saline was added to the reservoir and nebulized until "dry" (i.e. no aerosol was visibly generated by the nebulizer). No external gas source was required by the ultrasonic nebulizer. A similar quantity of salbutamol respirator solution and isotonic saline was placed inside the small ten millilitre medication cup supplied with the nebulizer by the manufacturer. The small cup was placed inside the standard twenty millilitre reservoir to which $10 \mathrm{~mL}$ of water had been added to serve as the coupling fluid for the transmission of vibration energy. Nebulization was allowed to continue until "dry".

\section{Outcome measures}

The infants were monitored continuously for their heart rate $(f \mathrm{C})$, respiratory rate $(f \mathrm{R})$, pulse oximetry (arterial oxygen saturation, $\left.\mathrm{Sa}, \mathrm{O}_{2}\right)$, and transcutaneous oxygen tension $\left(P t c, \mathrm{O}_{2}\right)$ and carbon dioxide tension $\left(P_{t c}, \mathrm{CO}_{2}\right)$ for $1 \mathrm{~h}$ after completion of aerosol delivery. The values of these parameters were recorded every minute except during, and for 2 min after, lung-function measurement. Immediately before aerosol delivery, baseline functional residual capacity (FRC), respiratory system compliance $(C \mathrm{rs})$ and resistance $(R \mathrm{rs})$ were measured using the Sensormedics Pulmonary Cart (Sensormedics, Yorba Linda, CA, USA). The measurements were repeated at $15 \mathrm{~min}, 30 \mathrm{~min}, 1 \mathrm{~h}$, and $2 \mathrm{~h}$ after completion of delivery. Aerosol administration and lung function measurements were carried out by two different investigators. Neither was involved in the clinical management of the infants, and the investigator performing the measurements was blinded to the method of aerosol delivery.

$C_{\text {rs }}$ and $R$ rs were measured using the passive flow-volume technique, which has been described previously [25]. In brief, the technique involves occlusion of the airway at end-inspiration to evoke the Hering Breuer reflex, which relaxes the respiratory muscles. The release of occlusion was followed by passive exhalation, and the expiratory flow was measured with a small dead space $(1.8 \mathrm{~mL})$ pneumotachograph connected to a Laerdal face mask held tightly over the infant's face. Airway occlusion was achieved by a pneumatically driven sliding valve incorporated in the pneumotachograph, which was also connected to a pressure transducer for the measurement of airway pressure. All the measurements were carried out during quiet breathing. A breath was accepted for analysis only when the occlusion pressure reached a stable plateau. $C$ rs and $R$ rs were obtained from the mean values of at least 10 acceptable breaths with a coefficient of variation of less than $10 \%$. FRC was estimated from the nitrogen concentration of the infants' exhaled breaths using the nitrogen washout method [26]. A constant flow of $100 \%$ oxygen washes the exhaled breaths through the face mask into a mixing chamber where the nitrogen concentration was analysed continuously with a nitrogen analyser. FRC was calculated by the computer from the total volume of nitrogen exhaled, and the concentration of alveolar nitrogen before and after washout. The measurement was performed twice each time and the mean value obtained for later analysis. 


\section{Statistics}

All parametric values were expressed as means ( \pm SEM), and the nonparametric values as medians. Repeated measurements by each device were compared using one-way repeated-measures analysis of variance (ANOVA). A comparison of the devices was made using one-way ANOVA or Friedman repeated-measures ANOVA on ranks where appropriate. When ANOVA showed a significant difference, the values were further analysed by Student-Newman-Keuls method for multiple pairwise comparison. For all comparisons, a significant difference was considered to be present when the probability of a type-I error is $<5 \%$ $(\mathrm{p}<0.05)$.

\section{Results}

There were 7 male and 3 female infants in Study A, and in Study B, 6 males and 4 females. Their demographic characteristics are given in table 1 . The MDI and spacer device took 2 min to deliver the prescribed dose of salbutamol. The nebulization time was about $15 \mathrm{~min}$ for the ultrasonic nebulizer and $13 \mathrm{~min}$ for the jet nebulizers. The experiments were carried out successfully in all the infants enrolled. Sufficient number of quiet breaths could be obtained from all infants for lung-function measurements without the need for sedation.

In both studies, immediately before aerosol delivery by each device, there were no significant differences in the $f \mathrm{C}, f \mathrm{R}, \mathrm{Sa}_{\mathrm{a}} \mathrm{O}_{2}, P_{t \mathrm{c}, \mathrm{O}_{2}}$ or $\mathrm{Ptc}_{\mathrm{tc}} \mathrm{CO}_{2}$ of the infants. There were also no significant differences between the infants in Study A and Study B. The overall mean ( \pm SEM) values of these para-

Table 1. - Demographic characteristics of the study infants

\begin{tabular}{lccc}
\hline & \multicolumn{2}{c}{ Mean (SEM) } & Range \\
\hline Study A n=10 & & & \\
Gestation weeks & 28.5 & $(0.6)$ & $26-32$ \\
Birth weight g & 1003 & $(46)$ & $855-1350$ \\
Postnatal age days & 41.4 & $(3.6)$ & $32-60$ \\
Body weight at study g & 1708 & $(120)$ & $1025-2200$ \\
$\mathrm{FI}_{\mathrm{I}, \mathrm{O}_{2}}$ & 0.27 & $(0.01)$ & $0.22-0.33$ \\
Study $\mathrm{B}=10$ & 28.3 & $(0.5)$ & $25.1-30.3$ \\
Gestation weeks & 1072 & $(59)$ & $875-1325$ \\
Birth weight g & 51.9 & $(6.0)$ & $30-88$ \\
Postnatal age days & 1874 & $(143)$ & $1115-2500$ \\
Body weight at study g & 0.24 & $(0.05)$ & $0.22-0.27$ \\
$\mathrm{~F}_{\mathrm{I}, \mathrm{O}_{2}}$ & & & \\
\hline
\end{tabular}

$\mathrm{F}_{\mathrm{I}, \mathrm{O}_{2}}$ : inspiratory oxygen fraction. meters were: $f \mathrm{C} 137.6(1.7)$ beats. $\mathrm{min}^{-1}, f \mathrm{R} 44.2$ (1.6) breaths $\min ^{-1}, \mathrm{Sa}_{\mathrm{a}} \mathrm{O}_{2} 95.5(0.4) \%, P_{t \mathrm{c}}, \mathrm{O}_{2} 10.3(0.1) \mathrm{kPa}$, and $P_{t \mathrm{c},}, \mathrm{CO}_{2}$ $4.3(0.1) \mathrm{kPa}$. Following aerosol delivery by the three devices, significant tachycardia was observed in all infants. The maximum $f \mathrm{C}$ ranged from $185-210$ beats $\cdot \mathrm{min}^{-1}$. Within the first $60 \mathrm{~min}$ after aerosol treatment, the areas under the curves (AOC) plotting the physiological parameters against time (table 2) show that in both studies a significantly higher $f \mathrm{C}$ was associated with the use of MDI or ultrasonic nebulizer than with the jet nebulizer; there was, however, no significant difference in $f \mathrm{R}$ or $\mathrm{Sa}, \mathrm{O}_{2}$ following the use of the different devices. In both studies, the ultrasonic nebulizer was associated with a significantly higher $P_{t c}, \mathrm{O}_{2}$ and lower $P t c, \mathrm{CO}_{2}$ when compared with the jet nebulizer. The differences between the ultrasonic nebulizer and MDI were statistically significant only in $P t c, \mathrm{O}_{2}$ in Study A. When the MDI and jet nebulizer were compared, the former was associated with a significantly lower $P_{t c}, \mathrm{CO}_{2}$ in Study B.

Before aerosol delivery via each of the devices, the baseline values of $C \mathrm{rs}, R \mathrm{rs}$, and FRC of the infants did not show any significant differences (table 3 ). In both studies, and with all devices, salbutamol treatment did not have any significant effect on $C$ rs (fig. 1 ). In contrast, $R$ rs decreased in all infants and reached a trough $30 \mathrm{~min}$ after treatment. Subsequently, $R$ rs gradually returned to the pretreatment values, and by $120 \mathrm{~min}, R \mathrm{rs}$ remained significantly lower than the pretreatment values only following ultrasonic nebulization (fig. 2). Table 4 shows the posttreatment decrease in Rrs expressed as a percentage of the pretreatment $R$ rs. The maximum mean (SEM) reduction from the pretreatment values observed at 30 min post-treatment following the use of the MDI, jet nebulizer, and ultrasonic nebulizer was $49.0(4.5) \%, 21.4(7.0) \%$, and $55.9(2.7) \%$, respectively in Study A ( $\mathrm{p}=0.0002)$, and $44.6(1.6) \%, 30.2$ (2.0)\%, and 55.4 (2.4)\%, respectively, in Study B ( $\mathrm{p}<0.0001)$. In Study A, the use of MDI or ultrasonic nebulizer was associated with a significantly greater improvement in $R$ rs than that with the jet nebulizer at 5, 30, and $60 \mathrm{~min}$ after aerosol delivery. In Study B, the differences were sustained up to 120 min after treatment. In both studies, improvement associated with the use of the ultrasonic nebulizer appeared to be greater than that with MDI, although statistically significant differences were observed only at 30 min after aerosol delivery in the infants in Study B.

Table 2. - Areas under the curves (AUC) plotting heart rate $(f C)$, respiratory rate $(f R)$, arterial oxygen saturation $\left(S a, \mathrm{O}_{2}\right)$, transcutaneous oxygen tension $\left(P_{\mathrm{tc}} \mathrm{O}_{2}\right)$ and carbon dioxide tension $\left(P_{\mathrm{tc}}, \mathrm{CO}_{2}\right)$ against time within the first 60 min after delivery of salbutamol aerosol

\begin{tabular}{|c|c|c|c|c|c|}
\hline \multirow[b]{2}{*}{ Device } & \multicolumn{5}{|c|}{ AUC: mean (SEM) (median for $P \mathrm{tc}, \mathrm{O}_{2}$ and $P \mathrm{tc}, \mathrm{CO}_{2}$ ) } \\
\hline & $f C$ & $f \mathrm{R}$ & $\mathrm{Sa}, \mathrm{O}_{2}$ & $P \mathrm{tc}, \mathrm{O}_{2}$ & $P \mathrm{tc}, \mathrm{CO}_{2}$ \\
\hline & & & & & \\
\hline MDI & 9953 (213) & $2970 \quad(85)$ & (111) & 5060 & 1644 \\
\hline Jet (Sidestream) & 9179 (135) & $3052(112)$ & 5761 & 4989 & 1765 \\
\hline Ultrasonic & 10069 (153) & $2967 \quad(89)$ & 5751 & 5239 & 1587 \\
\hline $\mathrm{p}^{*}$ & $<0.0001^{+}$ & 0.52 & 0.906 & $0.014 \#$ & 0.003 \\
\hline Study B: & & & & & \\
\hline MDI & 9628 (144) & $2698 \quad(90)$ & 5775 & 5327 & 1634 \\
\hline Jet (Hudson) & 9204 (157) & $2854 \quad(50)$ & 5787 & 5200 & 1795 \\
\hline Ultrasonic & $9714(150)$ & $2700 \quad(71)$ & 5843 & 5408 & 1616 \\
\hline $\mathrm{p}^{*}$ & $<0.0001^{+}$ & 0.074 & 0.625 & $0.008^{\S}$ & $0.007^{\dagger}$ \\
\hline
\end{tabular}

*: one-way repeated-measures ANOVA or Freidman repeated-measures ANOVA on ranks $\left(P \mathrm{tc}, \mathrm{O}_{2}\right.$ and $\left.P \mathrm{tc}, \mathrm{CO}_{2}\right)$. Multiple pairwise comparisons by the Student-Newman-Keuls method $(\mathrm{p}<0.05)$ : +: MDI or Ultrasonic $>$ Jet (both models); \#: Ultrasonic $>$ MDI or Jet $($ Side-

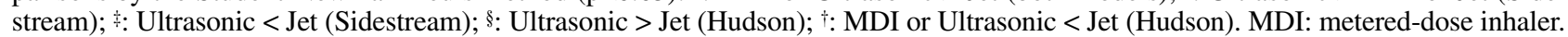


Figure 3 shows that in both studies, the FRC of the infants improved only following aerosol delivery by the MDI or ultrasonic nebulizer. The pattern of improvement was similar to that in $R \mathrm{rs}$, with peak values being observed at $30 \mathrm{~min}$, after which FRC gradually returned to the pretreatment values. There was no significant change in FRC throughout the study period after jet nebulization. The percentage change in FRC from the pre-treatment values is shown in table 5. Compared with the jet nebulizer, aerosol

Table 3. - Baseline values of respiratory system compliance $\left(C_{\mathrm{rs}} \cdot \mathrm{kg}^{-1}\right)$, respiratory system resistance (Rrs), and functional residual capacity (FRC. $\mathrm{kg}^{-1}$ ) immediately before salbutamol treatment via each of the delivery devices

\begin{tabular}{lccc}
\hline Device & $\begin{array}{c}C_{\mathrm{rs} \cdot \mathrm{kg}^{-1}} \\
\mathrm{~mL} \cdot \mathrm{kPa}^{-1} \cdot \mathrm{kg}^{-1}\end{array}$ & $\begin{array}{c}R \mathrm{rs} \\
\mathrm{kPa} \cdot \mathrm{L}^{-1} \cdot \mathrm{s}^{-1}\end{array}$ & $\begin{array}{c}\mathrm{FRC} \\
\mathrm{mL} \cdot \mathrm{kg}^{-1}\end{array}$ \\
\hline Study A & & & \\
MDI & $17.5(1.8)$ & $10.0(1.0)$ & $17.1(0.9)$ \\
Jet (Sidestream) & $19.2(1.9)$ & $9.9(1.2)$ & $17.0(1.1)$ \\
Ultrasonic & $16.1(2.0)$ & $10.5(1.1)$ & $16.7(1.0)$ \\
p* & 0.173 & 0.315 & 0.952 \\
Study B & & & \\
MDI & $15.7(1.6)$ & $8.8(0.8)$ & $18.0(0.4)$ \\
Jet (Hudson) & $15.2(1.5)$ & $8.4(0.8)$ & $18.4(0.6)$ \\
Ultrasonic & $14.8(1.8)$ & $8.9(0.8)$ & $18.3(0.5)$ \\
p* & 0.873 & 0.100 & 0.088 \\
\hline
\end{tabular}

Values presented as mean \pm sem. $*$ : one-way repeated-measures ANOVA. MDI: metered-dose inhaler.

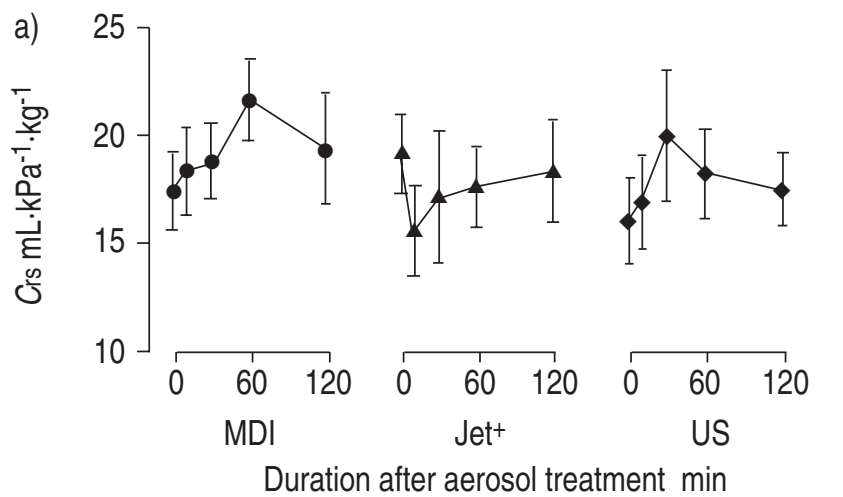

delivery by the ultrasonic nebulizer had resulted in a significantly greater increase in FRC at 15 and $30 \mathrm{~min}$ in Study A. In Study B, the use of the MDI-Aerochamber was associated with the greatest FRC improvement, which was significantly greater than that with the jet nebulizer from 15-60 min of aerosol delivery.

\section{Discussion}

The evaluation of aerosol delivery devices in newborns based on pulmonary deposition might be misleading since, in the small infants, the deposition per kilogram of body weight might be greater than that in adults, despite an apparently small absolute lung dose. It is, therefore, clinically more relevant to compare the physiological effects of a pharmacological aerosol delivered by the devices. Using a short- and fast-acting bronchodilator (salbutamol) whose pharmacological effects could be readily assessed, the present studies provided a direct comparison between an ultrasonic nebulizer-small cup device, an MDI used in conjunction with a modified (non-valved) Aerochamber, and two commercially available jet nebulizers. Although the salbutamol-MDI used in this study contains chlorofluorocarbon (CFC) propellants that are to be phased out in the near future, the device will likely continue to be used for several years in many countries. Furthermore, the comparison would be of particular clinical relevance if future non-CFC MDIs are formulated to have similar output

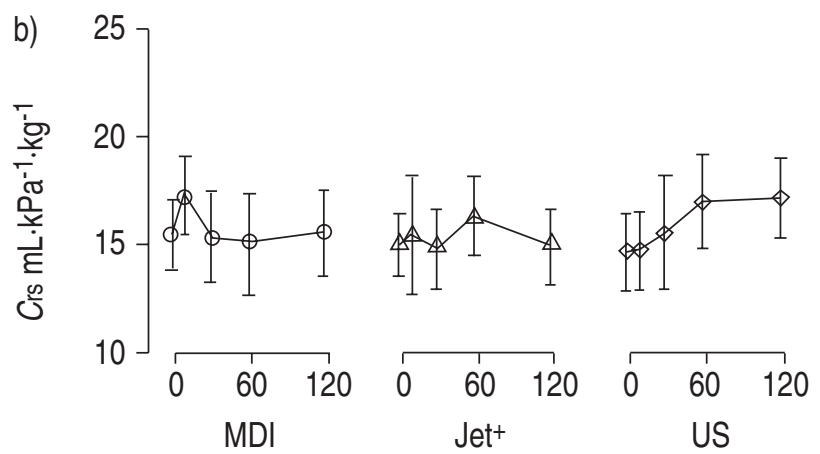

Duration after aerosol treatment $\mathrm{min}$

Fig. 1. - Measurements of respiratory system compliance $\left(C_{\mathrm{rs}} \cdot \mathrm{kg}^{-1}\right)$ before, and at $15,30,60$ and 120 min after salbutamol treatment via the metered dose inhaler plus Aerochamber (MDI), the jet nebulizer (Jet) and the ultrasonic nebulizer (US) in a) study A and b) study B. +: in a) jet=Sidestream and b) jet=Hudson. In both studies, and with all three types of devices, there were no statistically significant differences between the pre- and post-treatment values at any time points.
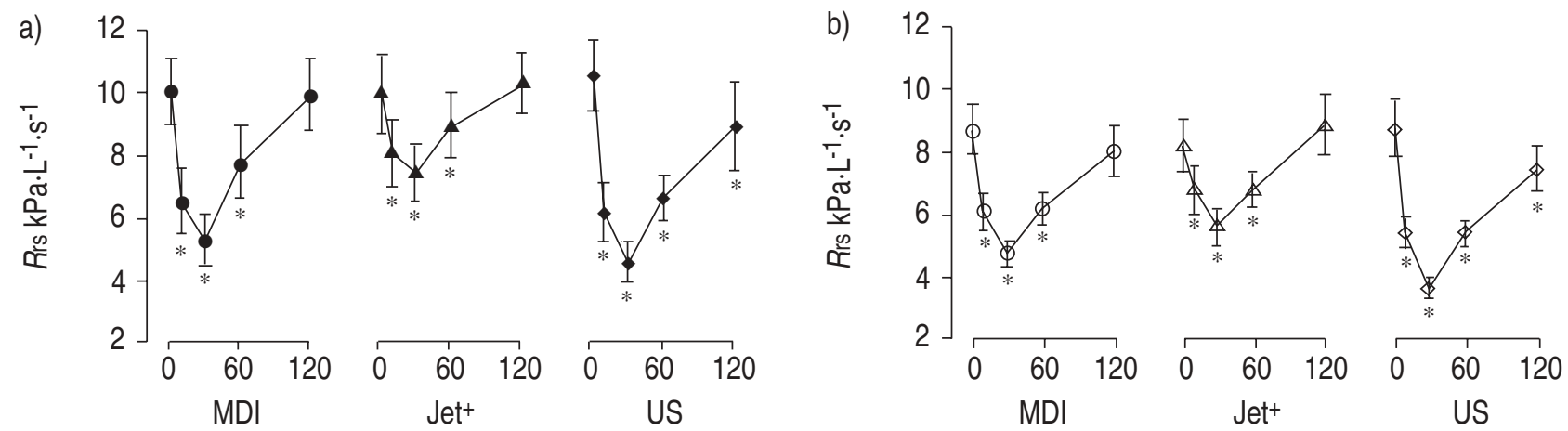

Duration after aerosol treatment min

Duration after aerosol treatment min

Fig. 2. - Measurements of respiratory system resistance ( $R \mathrm{rs})$ before, and at 15, 30, 60 and 120 min after salbutamol treatment via the metered dose inhaler plus Aerochamber (MDI), the jet nebulizer (Jet) and the ultrasonic nebulizer (US) in a) study A and b) study B. +: in a) jet=Sidestream and b) jet=Hudson. *: post-treatment values were significantly lower than the pre-treatment $R \mathrm{rs}$, as shown by one-way repeated-measures ANOVA (p $<0.0001$ with all three devices in both studies) and multiple pairwise comparison using the Student-Newman-Keuls method ( $\mathrm{p}<0.05$ ). 
Table 4. - Percentage change in respiratory system resistance (Rrs) from the pre-treatment values at $15,30,60$ and 120 min after aerosol treatment

\begin{tabular}{|c|c|c|c|c|}
\hline \multirow[b]{2}{*}{ Device } & \multicolumn{4}{|c|}{ Percentage change in $R$ rs: mean (SEM) } \\
\hline & $15 \mathrm{~min}$ & $30 \mathrm{~min}$ & $60 \mathrm{~min}$ & $120 \mathrm{~min}$ \\
\hline \multicolumn{5}{|l|}{ Study A } \\
\hline MDI & $-37.6 \quad(4.3)$ & $-49.0 \quad(4.5)$ & $-25.3 \quad(4.0)$ & $-2.0(3.2)$ \\
\hline Jet (Sidestream) & $-17.9 \quad(3.9)$ & $-21.4 \quad(7.0)$ & $-6.3(7.7)$ & $9.2(9.4)$ \\
\hline Ultrasonic & -40.9 (4.6) & $-55.9(2.7)$ & $-34.3 \quad(4.4)$ & $-15.6(5.6)$ \\
\hline $\mathrm{p}^{*}$ & $0.0003^{+}$ & $0.0002^{+}$ & $0.007^{\#}$ & 0.06 \\
\hline \multicolumn{5}{|l|}{ Study B } \\
\hline MDI & $-28.5 \quad(2.7)$ & $-44.6 \quad(1.6)$ & $-27.4 \quad(2.5)$ & $-7.6(2.1)$ \\
\hline Jet (Hudson) & $-16.5 \quad(1.8)$ & $-30.2 \quad(2.0)$ & $-15.0 \quad(2.7)$ & $8.3(3.1)$ \\
\hline Ultrasonic & $-34.9 \quad(3.7)$ & $-55.4 \quad(2.4)$ & $-33.8 \quad(4.2)$ & $-12.7(2.1)$ \\
\hline $\mathrm{p}^{*}$ & $0.0006^{+}$ & $<0.0001^{\ddagger}$ & $<0.0001^{+}$ & $0.0001^{+}$ \\
\hline
\end{tabular}

*: one-way repeated-measures ANOVA. Multiple pairwise comparison by the Student-Newman-Keuls test (p<0.05): ${ }^{+:}$MDI or Ultrasonic > Jet (both models); \#: Ultrasonic > Jet (Sidestream); *: Ultrasonic > MDI > Jet (Hudson). MDI: metered-dose inhaler.

Table 5. - Percentage change in functional residual capacity (FRC) from the pre-treatment values at 15, 30, 60 and 120 min after aerosol treatment

\begin{tabular}{|c|c|c|c|c|}
\hline \multirow[b]{2}{*}{ Device } & \multicolumn{4}{|c|}{ Percentage change in FRC: mean (SEM) } \\
\hline & $15 \mathrm{~min}$ & $30 \mathrm{~min}$ & $60 \mathrm{~min}$ & $120 \mathrm{~min}$ \\
\hline \multicolumn{5}{|l|}{ Study 1} \\
\hline MDI & $5.4(2.8)$ & $10.0(3.0)$ & $6.1(2.9)$ & $-3.3(3.1)$ \\
\hline Jet (Sidestream) & $-2.9(4.9)$ & $2.7 \quad(3.8)$ & $-0.7 \quad(6.0)$ & $1.2(5.5)$ \\
\hline Ultrasonic & $10.7 \quad(2.7)$ & $15.4(3.4)$ & $5.8 \quad(2.2)$ & $7.6(2.1)$ \\
\hline $\mathrm{p}^{*}$ & $0.043^{+}$ & $0.005^{+}$ & 0.391 & 0.095 \\
\hline \multicolumn{5}{|l|}{ Study 2} \\
\hline MDI & $6.9(1.6)$ & $9.9(1.2)$ & $8.1 \quad(1.2)$ & $4.8(1.7)$ \\
\hline Jet (Hudson) & $0.6(1.0)$ & $1.6(1.1)$ & $1.7(1.2)$ & $0.6(1.9)$ \\
\hline Ultrasonic & $4.5 \quad(0.5)$ & $6.2(1.3)$ & 4.8 (1.3) & $3.1(1.2)$ \\
\hline $\mathrm{p}^{*}$ & $0.002^{\#}$ & $0.0001^{\ddagger}$ & $0.004 \S$ & 0.20 \\
\hline
\end{tabular}

*: one-way repeated-measures ANOVA. Multiple pairwise comparison by Student-Newman-Keuls test ( $<<0.05)$ : +: Ultrasonic $>$ Jet (Sidestream); \#: MDI or Ultrasonic > Jet (Hudson); \$: MDI > Ultrasonic > Jet (Hudson); §: MDI > Jet (Hudson). MDI: metered-dose inhaler.
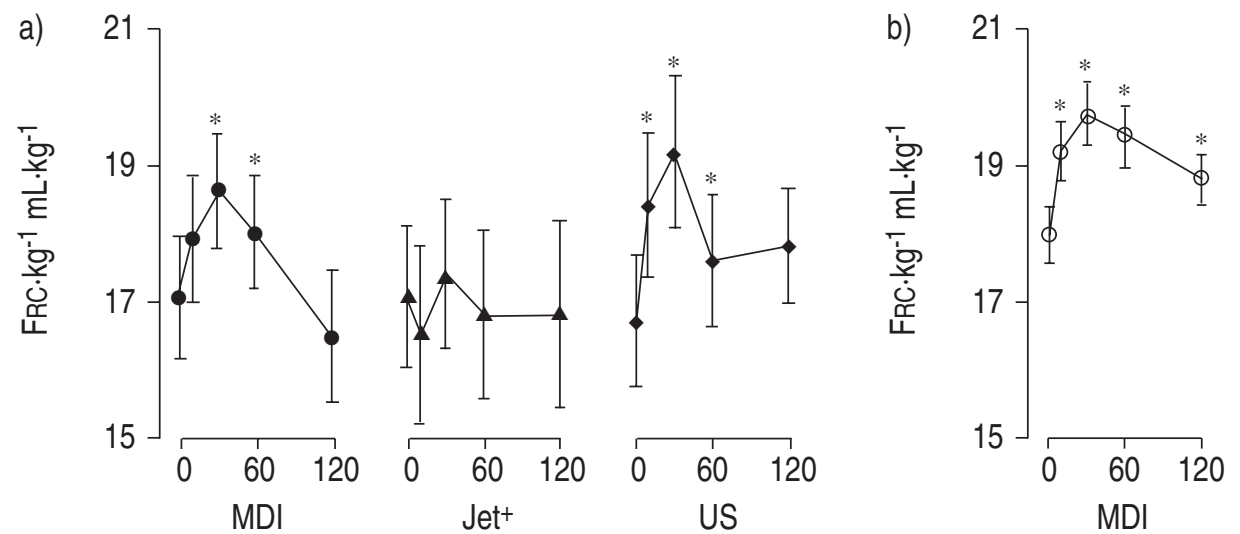

Duration after aerosol treatment $\min$
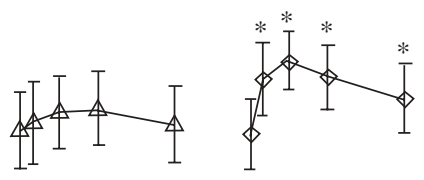

Duration after aerosol treatment $\mathrm{min}$

Fig. 3. - Measurements of functional residual capacity (FRC $\cdot \mathrm{kg}^{-1}$ ) before, and at 15, 30, 60 and $120 \mathrm{~min}$ after salbutamol treatment via the metered dose inhaler plus Aerochamber (MDI), the jet nebulizer (Jet) and the ultrasonic nebulizer (US) in a) study A and b) study B. +: in a) jet=Sidestream and b) jet=Hudson. *: post-treatment values were significantly lower than the pre-treatment FRC, as shown by one-way repeated-measures ANOVA ( $<<0.0001$ for MDI and US in both studies) and multiple pairwise comparison using the Student-Newman-Keuls method ( $<<0.05)$. In both studies, none of the post-treatment values after jet nebulization was significantly different from the pre-treatment values.

characteristics as the CFC-MDIs. The particle sizes of the aerosol generated by these devices have been determined in previous studies, and are all within the respirable range with a mass median aerodynamic diameter of $1-2 \mu \mathrm{m}[12$, $21,22]$. In all infants, a standard nominal dose of salbutamol has resulted in a greater pharmacological response when delivered by the MDI-Aerochamber or ultrasonic nebulizer than that by the jet nebulizer. This included a more significant increase in $f \mathrm{C}$, a greater, though variable, decrease in $P \mathrm{tc}, \mathrm{CO}_{2}$, and a greater improvement in $R \mathrm{rs}$ and FRC. The maximum reduction in Rrs following the use of the MDI-Aerochamber or ultrasonic nebulizer was $>2$ and 1.5 times that associated with the Sidestream and the Hudson jet nebulizer, respectively. Since a significant proportion of total airway resistance originates from the upper and conducting airway, which does not respond to bronchodilators [27], the absolute difference in the reduction of lower respiratory tract resistance should be even greater.

An increase in FRC was observed, following the use of the MDI or ultrasonic nebulizer but not the jet nebulizer. An improvement in FRC after salbutamol treatment is like- 
ly to be secondary to bronchodilation: in chronic lung disease, some lung compartments fail to equilibrate with the inspired gas due to airway obstruction, resulting in an underestimation of FRC by the nitrogen washout technique [28]. In contrast to Rrs and FRC, there was no significant improvement in $C$ rs after treatment by any of the devices tested. An improvement in $C$ rs following relief of bronchial constriction is possibly caused by recruitment of atelectatic alveoli, and may not be demonstrable in infants with mild chronic lung changes not associated with any significant alveolar atelectasis.

Compared with the MDI-Aerochamber, the ultrasonic nebulizer was associated with an apparently greater degree of reduction in $R$ rs following aerosol delivery. The difference was, however, small and significant only at $30 \mathrm{~min}$ in Study B. Furthermore, since the time of aerosol delivery was 2 min for the MDI and $15 \mathrm{~min}$ for the ultrasonic nebulizer, the aerosol from the latter device had a longer time to act on the lungs before Rrs was measured. Given this potential source of bias, we do not consider it appropriate to draw a definite conclusion in favour of the ultrasonic nebulizer.

A major limitation in the use of bronchodilator aerosol in small infants is the small amount of medication that can reach the infants' lungs. Our findings show that among the currently available devices, the ultrasonic nebulizer used together with a small medication cup and the metered-dose inhaler used in conjunction with a non-valved Aerochamber are more efficient than the jet nebulizer in relieving bronchiolar constriction in infants with chronic lung disease. Although the findings are limited only to the devices tested and might not be generalizable to other devices, our results should provide a useful reference for paediatricians in their choice of aerosol delivery system for the treatment of reversible airway disease in this category of infants.

\section{References}

1. Kao LC, Warburton D, Platzker ACG, Keens TG. Effect of isoproterenol inhalation on airway resistance in chronic bronchopulmonary dysplasia. Pediatrics 1984; 73: 509-514.

2. Yuksel B, Greenough A, Maconochie I. Effective bronchodilator treatment by a simple spacer device for wheezy premature infants. Arch Dis Child 1990; 65: 782-785.

3. Kraemer R, Birrer P, Modelska K, Aebischer CC, Schöni $\mathrm{MH}$. A new baby-spacer device for aerosolized bronchodilator administration in infants with bronchopulmonary dysplasia. Eur J Pediatr 1992; 151: 57-60.

4. Wilkie RA, Bryan MH. Effect of bronchodilators on airway resistance in ventilator-dependent neonates with chronic lung disease. J Pediatr 1987; 111: 278-282.

5. Motoyama EK, Fort MD, Klesh KW, Mutich RL, Guthrie RD. Early onset airway reactivity in premature infants with bronchopulmonary dysplasia. Am Rev Respir Dis 1987; 136: 50-57.

6. Rotschild A, Solimano A, Puterman M, Smyth J, Sharma $\mathrm{A}$, Albersheim S. Increased compliance in response to salbutamol in premature infants with developing bronchopulmonary dysplasia. J Pediatr 1989; 115: 984-991.

7. Brundage KL, Mohsini KG, Froese AB, Fisher JT. Bronchodilator response to ipratropium bromide in infants with bronchopulmonary dysplasia. Am Rev Respir Dis 1990; 142: 1137-1142.

8. Pfenninger J, Aebi C. Respiratory response to salbutamol (albuterol) in ventilator-dependent infants with chronic lung disease: pressurized aerosol delivery versus intravenous injection. Intensive Care Med 1993; 19: 251255.
9. Lee H, Arnon S, Silverman M. Bronchodilator aerosol administered by metered dose inhaler and spacer in subacute neonatal respiratory distress syndrome. Arch Dis Child 1994; 70: F218-F222.

10. Watterberg KL, Clark AR, Kelly HW, Murphy S. Delivery of aerosolized medication to intubated babies. Pediatr Pulmonol 1991; 10: 136-141.

11. Grigg J, Arnon S, Jones T, Clarke A, Silverman M. Delivery of therapeutic aerosols to intubated infants. Arch Dis Child 1992; 67: 25-30.

12. Fok TF, Dolovich M, Gray S, Coates G, Paes B, Rashid F, Newhouse M, Kirpalani H. Efficiency of aerosol medication delivery from a metered dose inhaler versus jet nebuliser in infants with bronchopulmonary dysplasia. Pediatr Pulmonol 1996; 21: 301-309.

13. Flavin M, MacDonald M, Dolovich M, Coates G, O'Brodovich H. Aerosol delivery to the rabbit lung with an infant ventilator. Pediatr Pulmonol 1986; 2: 35-39.

14. Cameron D, Arnot R, Clay M, Silverman M. Aerosol delivery in neonatal ventilator circuits: a rabbit lung model. Pediatr Pulmonol 1991; 10: 208-213.

15. Cameron D, Clay M, Silverman M. Evaluation of nebulizers for use in neonatal ventilator circuits. Crit Care Med 1990; 18: 866-870.

16. Arnon S, Grigg J, Nikander K, Silverman M. Delivery of micronized budesonide suspension by metered dose inhaler and jet nebulizer into neonatal ventilator circuit. Pediatr Pulmonol 1992; 13: 172-175.

17. Everard ML, Stammers J, Hardy JG, Milner AD. New aerosol delivery system for neonatal ventilator circuits. Arch Dis Child 1992; 67: 826-830.

18. O'Callaghan C, Hardy J, Stammers J, Stephenson TJ, Hull D. Evaluation of techniques for delivery of steroids to lungs of neonates using a rabbit model. Arch Dis Child 1992; 67: 20-24.

19. Salmon B, Wilson NM, Silverman M. How much aerosol reaches the lungs of wheezy infants and toddlers? Arch Dis Child 1990; 65: 401-403.

20. Gappa M, Gartner M, Poets CF, von der Hardt H. Effects of salbutamol delivery from a metered dose inhaler versus jet nebulizer on dynamic lung mechanics in very preterm infants with chronic lung disease. Pediatr Pulmonol 1997; 23: 442-448.

21. Fok TF, Lam K, Chan CK, et al. Aerosol delivery to nonventilated infants by metered dose inhaler: should a valved spacer be used? Pediatr Pulmonol 1997; 24: 204-212.

22. Fok TF, Al-essa M, Monkman S, et al. Pulmonary deposition of albuterol aerosol delivered by metered-dose inhaler, jet nebulizer and ultrasonic nebulizer in mechanically ventilated rabbits. Pediatr Res 1997; 42: 721-727.

23. Northway WH, Rosan RC, Peter DY. Pulmonary disease following respiratory therapy of hyaline-membrane disease. Bronchopulmonary dysplasia. N Engl J Med 1967; 276: 357-368.

24. Bancalari E, Abdenour GE, Feller R, Gannon J. Bronchopulmonary dysplasia: clinical presentation. J Pediatr 1979; 85: 819-823.

25. LeSouëf PN, England SJ, Bryan AC. Passive respiratory mechanics in newborns and children. Am Rev Respir Dis 1984; 129: 552-556.

26. Gerhardt T, Hehre D, Bancalari E, Watson H. A simple method for measuring functional residual capacity by $\mathrm{N}_{2}$ washout in small animals and newborn infants. Pediatr Res 1985; 19: 1165-1169.

27. LeSouëf PN, England SJ, Bryan AC. Total resistance of the respiratory system in preterm infants with and without an endotracheal tube. J Pediatr 1984; 104: 108-111.

28. Jalowayski AA, Dawson A. Measurement of lung volume: the multiple breath nitrogen method. In: Clausen JL, ed. Pulmonary function testing guidelines and controversies. New York, Academic Press Inc., 1982: p. 115. 